\title{
TAK1 inhibitor 5Z-7-oxozeaenol sensitizes cervical cancer to doxorubicin-induced apoptosis
}

\author{
Shan Guan ${ }^{1,2}$, Jiaxiong Lu², Yanling Zhao ${ }^{2}$, Sarah E. Woodfield ${ }^{3}$, Huiyuan Zhang ${ }^{2}$, \\ Xin $\mathrm{Xu}^{2}$, Yang $\mathrm{Yu}^{2}$, Jing Zhao ${ }^{1}$, Shayahati Bieerkehazhi ${ }^{4}$, Haoqian Liang ${ }^{2,5}$, Jianhua \\ Yang ${ }^{2}$, Fuchun Zhang ${ }^{1}$, Surong Sun ${ }^{1}$ \\ ${ }^{1}$ Xinjiang Key Laboratory of Biological Resources and Genetic Engineering, College of Life Science and Technology, Xinjiang \\ University, Urumqi, Xinjiang 830046, China \\ ${ }^{2}$ Texas Children's Cancer Center, Department of Pediatrics, Dan L. Duncan Cancer Center, Baylor College of Medicine, \\ Houston, TX 77030, USA \\ ${ }^{3}$ Division of Pediatric Surgery, Michael E. DeBakey Department of Surgery, Dan L. Duncan Cancer Center, Baylor College of \\ Medicine, Houston, TX 77030, USA \\ ${ }^{4}$ Department of Labour Hygiene and Sanitary Science, College of Public Health, Xinjiang Medical University, Urumqi, Xinjiang \\ 830011, China \\ ${ }^{5}$ School of Pharmacy, Zhengzhou University, Zhengzhou, Henan 450001, China \\ Correspondence to: Surong Sun, email: sr_sun2005@163.com \\ Fuchun Zhang, email: zfcxju@xju.edu.cn
}

Keywords: cervical cancer, TAK1 inhibitor, 5Z-7-oxozeaenol, chemotherapy, doxorubicin

Received: February 22, $2017 \quad$ Accepted: March 28, $2017 \quad$ Published: April 06, 2017

Copyright: Guan et al. This is an open-access article distributed under the terms of the Creative Commons Attribution License (CC-BY), which permits unrestricted use, distribution, and reproduction in any medium, provided the original author and source are credited.

\section{ABSTRACT}

Aberrant activation of nuclear factor-KB (NF-KB) allows cancer cells to escape chemotherapy-induced cell death and acts as one of the major mechanisms of acquired chemoresistance in cervical cancer. TAK1, a crucial mediator that upregulates NF-KB activation in response to cellular genotoxic stress, is required for tumor cell viability and survival. Herein, we examined whether TAK1 inhibition is a potential therapeutic strategy for treating cervical cancer. We found that TAK1 inhibitor 5Z-7-oxozeaenol significantly augmented the cytotoxic effects of Dox in a panel of cervical cancer cell lines. Treatment with 5Z-7-oxozeaenol hindered Dox-induced NF-kB activation and promoted Dox-induced apoptosis in cervical cancer cells. Moreover, 5Z-7-oxozeaenol showed similar effects in both positive and negative human papillomavirus-infected cervical cancer cells. Taken together, our results provide evidence that TAK1 inhibition significantly sensitizes cervical cancer cells to chemotherapy-induced cell death and supports the use of TAK1 inhibitor with current chemotherapies in the clinic for patients with refractory cervical cancer.

\section{INTRODUCTION}

As the second leading cause of cancer-related deaths in women, cervical cancer is a major health problem with an evergrowing threat worldwide [1-3]. Despite that, more than $80 \%$ of early period and $60 \%$ of loco-regionally advanced cervical cancers exhibit good outcomes with current treatment regimens [4]. However, due to resistance mechanisms, the effects of chemotherapeutic and radiotherapeutic agents, such as the traditional chemotherapies doxorubicin (Dox) and etoposide (VP-16), are thereby reduced [5-7].

Transcription factor nuclear factor- $\kappa \mathrm{B}(\mathrm{NF}-\kappa \mathrm{B})$, known as one of the critical mediators of diverse functions in cancer cells, is involved in inflammatory cellular responses to stimuli such as stress, cytokines, free radicals, ultraviolet irradiation, oxidized low-density-lipoprotein (LDL), and bacterial and viral antigens [8-10]. Aberrant activation of $\mathrm{NF}-\kappa \mathrm{B}$ is frequently seen in tumor cells, including cervical cancer cells, and is believed to be one of the reasons for the development of resistance mechanisms that contribute to resistance to current chemo- and radiotherapies [11-13]. In cervical carcinoma, the majority of chemotherapies, radiotherapies, and combinations of chemo- and radiotherapies activate the $\mathrm{NF}-\kappa \mathrm{B}$ signaling pathway, which results in abnormally increased NF- $\kappa \mathrm{B}$ expressionand, in turn, promotes the development of refractory disease [14].

TAK1, one of the mitogen-activated protein kinase (MAPK) family members, is reported as a pivotal intermediate 
for activation of transforming growth factor- $\beta$ (TGF- $\beta$ ), I $\mathrm{KB}$ kinase (IKK), or MAPK, as well as a critical player in innate and adaptive immune responses [15-20]. In addition, it has been widely proven to be a crucial mediator of upregulation of NF- $\kappa \mathrm{B}$ activation in response to genotoxic stress or Dox exposure [21-25]. Accordingly, NF- $\kappa \mathrm{B}$ activation accelerates chemoresistance induced by conventional chemotherapies and promotes tumor cell viability. Thus, inhibition of TAK1 blocks $\mathrm{NF}-\kappa \mathrm{B}$ activation, resulting in the death of more vulnerable cancer cells in studies of colon cancer [26], leukemia [27, 28], cerebral ischemia [29], and cervical cancer [4]. Therefore, TAK1 inhibition to inactivate the NF- $\kappa B$ pathway is a promising therapeutic strategy [30-32].

5Z-7-oxozeaenol (5Z-7) is a novel TAK1 inhibitor that significantly augments the cytotoxic effects of Dox and VP-16 [33]. 5Z-7 efficiently overcomes chemoresistance induced by $\mathrm{NF}-\kappa \mathrm{B}$ activation [33-35] and exhibits strong efficacy in studies of breast cancer [36], neuroblastoma [37], and lymphoma [38]. However, the effects of 5Z-7 in cervical cancer remains unknown.

In this study, we evaluate the therapeutic effects of the TAK1 inhibitor 5Z-7 on cervical cancer. Our results demonstrate that 5Z-7 significantly augments the cytotoxic effects of Dox in a panel of cervical cancer cell lines. Treatment with 5Z-7 enhances the anti-proliferative effects of Dox in an anchorage-independent manner, hinders Doxinduced NF- $\kappa$ B activation, and increases Dox-induced apoptosis. Interestingly, 5Z-7 showed similar effect in both positive and negative human papillomavirus (HPV)-infected cervical cancer cells. Importantly, our preclinical study of 5Z-7 supports further studies of TAK 1 inhibitor and its potential use in the clinic for patients with refractory cervical cancer.

\section{RESULTS}

\section{TAK1 inhibitor 5Z-7-oxozeaenol exhibits cytotoxic effect on cervical cancer cells}

To determine the inhibitory effects of 5Z-7 on cervical cancer cell lines, we conducted the MTT assay on five cervical cancer cell lines, including HeLa, C-33-A, Ca Ski, ME-180 and SiHa (Figure 1A). The IC50s of $5 \mathrm{Z}-7$ on these cell lines were calculated and ranked from $1.34 \mu \mathrm{M}$ to $7.82 \mu \mathrm{M}$ (Figure 1A). The results exhibited that TAK1 inhibitor 5Z-7 could inhibit cervical cancer cell proliferation (Figure 1A, 1B).

\section{TAK1 inhibitor 5Z-7-oxozeaenol significantly increases the cytotoxic effect of Dox on cervical cancer cells}

To identify whether TAK1 inhibitor 5Z-7 could

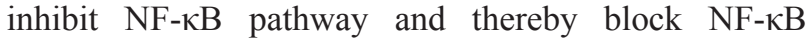
activation-induced chemoresistance, we treated a panel of five cervical cancer cell lines, including HeLa, C-33-A, Ca Ski, ME-180 and SiHa, with Dox, a NF- $\kappa$ B activator, and the TAK1 inhibitor 5Z-7 for $48 \mathrm{~h}$ (Figure 2A). To uncover the combination effect of 5Z-7 and Dox on cell proliferation, we performed colony formation assay to detect anti-proliferation effects of 5Z-7 and Dox combinations (Figure 2B). The results of both CCK-8 and colony formation assays with these cells demonstrate that TAK1 inhibition significantly enhances the cytotoxic effect of Dox on cervical cancer cells, as compared to the cells treated with either single agent. In addition, the efficacy of 5Z-7 is independent of HPV virus status, since both HPV positive (HeLa, Ca Ski, ME-180, SiHa) and HPV negative (C-33-A) cervical cell lines showed similar results.

\section{TAK1 inhibitor 5Z-7-oxozeaenol strengthens the Dox-mediated inhibitory effects on anchorage- independent growth of cervical cancer cells}

To test the effect of inhibition of TAK1 in combination with Dox on anchorage-independent growth abilities, soft agar assays were performed with HPV positive HeLa and HPV negative C-33-A treated with a combination of the two drugs. Although single use of low dose $5 \mathrm{Z}-7(0.5 \mu \mathrm{M})$ could not inhibit anchorageindependent cell growth, the combination with Dox could significantly strengthen the Dox-induced inhibitory effects of anchorage-independent growth on HeLa (Figure 3A) and C-33-A (Figure 3B) cells. Consistently in contrast to single Dox treatment, the combination of 5Z-7 and Dox significantly decreased colony numbers of HeLa (Figure 3C) and C-33-A cell lines (Figure 3D). These results indicate that the $5 \mathrm{Z}-7$ could significantly strengthen the Dox-induced inhibitory effects of anchorageindependent growth abilities on cervical cancer cells.

\section{TAK1 inhibitor 5Z-7-oxozeaenol enhances Dox- induced apoptosis on cervical cancer cells}

Owing that single 5Z-7 treatment exhibited inhibitory efficacy on cervical cancer cells, we then tested its combinatory effects with conventional compound Dox. The results demonstrate that by strong contrast to single Dox treatment, the combination of Dox with 5Z-7 greatly increased PARP and Caspase 3 cleavages (Figure 4A-4E). These data indicate that 5Z-7 enhances Dox-induced apoptosis.

\section{TAK1 inhibitor 5Z-7-oxozeaenol suppresses Dox- induced NF-кB, JNK and p38 signaling}

NF- $\kappa \mathrm{B}$ isan important transcriptional factor associated with tumor growth and cell survival [39, 40]. According to prior studies, TAK1 inhibition-mediated cell death is associated with inhibition of NF- $\kappa \mathrm{B}$ and $\mathrm{JNK} /$ MAPK signal pathway. We therefore hypothesized that $5 Z-7$ would block the activation of NF- $\kappa \mathrm{B}, \mathrm{JNK}$ and p38 signaling. To investigate this hypothesis HeLa and C-33-A cells were treated with Dox or in combinations with 5Z-7. The results indicate that TAK 1 inhibition by $5 Z-7$ significantly stabilizes $\mathrm{I} \kappa \mathrm{B} \alpha$ and in turn suppresses NF- $\kappa \mathrm{B}$ 
activation (Figure 5A, 5B). The treatment also successfully blocks Dox-induced JNK and p38 phosphorylation (Figure 5A, 5B). These data signify that TAK1 is required for Dox-induced pathways activation such as NF- $\kappa B$, JNK and p38 in cervical cancer cells. And 5Z-7 works as a TAK1 inhibitor to block Dox induced NF- $\kappa$ B, JNK and p38 activation in cervical cancer cells.

\section{DISCUSSION}

Uncovering the molecular mechanisms that mediate chemoresistance of recurrent and refractory cervical cancer patients is getting increased interest [41, 42]. $\mathrm{NF}-\kappa \mathrm{B}$ has been shown to be one of the most important transcriptional factors promoting tumor cell survival and plays an important role in cervical cancer development
[39, 40]. According to prior studies, the activation of $\mathrm{NF}-\kappa \mathrm{B}$ contributes to chemotherapy resistance $[11,12]$, and the inhibition of NF- $\kappa \mathrm{B}$ could enhance cytotoxic effects of chemotherapeutic drugs in cervical cancer [43]. Since it is clear that TAK1 plays a pivotal role in chemotherapy-induced NF- $\kappa \mathrm{B}$ activation, we surmised that inhibition of TAK 1 activation would block chemotherapy resistance induced by $\mathrm{NF}-\kappa \mathrm{B}$ activation and increase the efficacy of conventional chemotherapeutic agents.

5Z-7, is a novel TAK1 inhibitor that has been studied in lymphoma [38], neuroblastoma [37], fibroblasts [44] and breast cancer [45]. A closely related analog of 5Z-7, termed E6201, is in phase II clinical trials by Eisai Inc., for the treatment of melanoma, as well as being a possible topical agent for treatment of psoriasis [45]. And based on prior studies, treatment with $5 \mathrm{Z}-7$ significantly

A
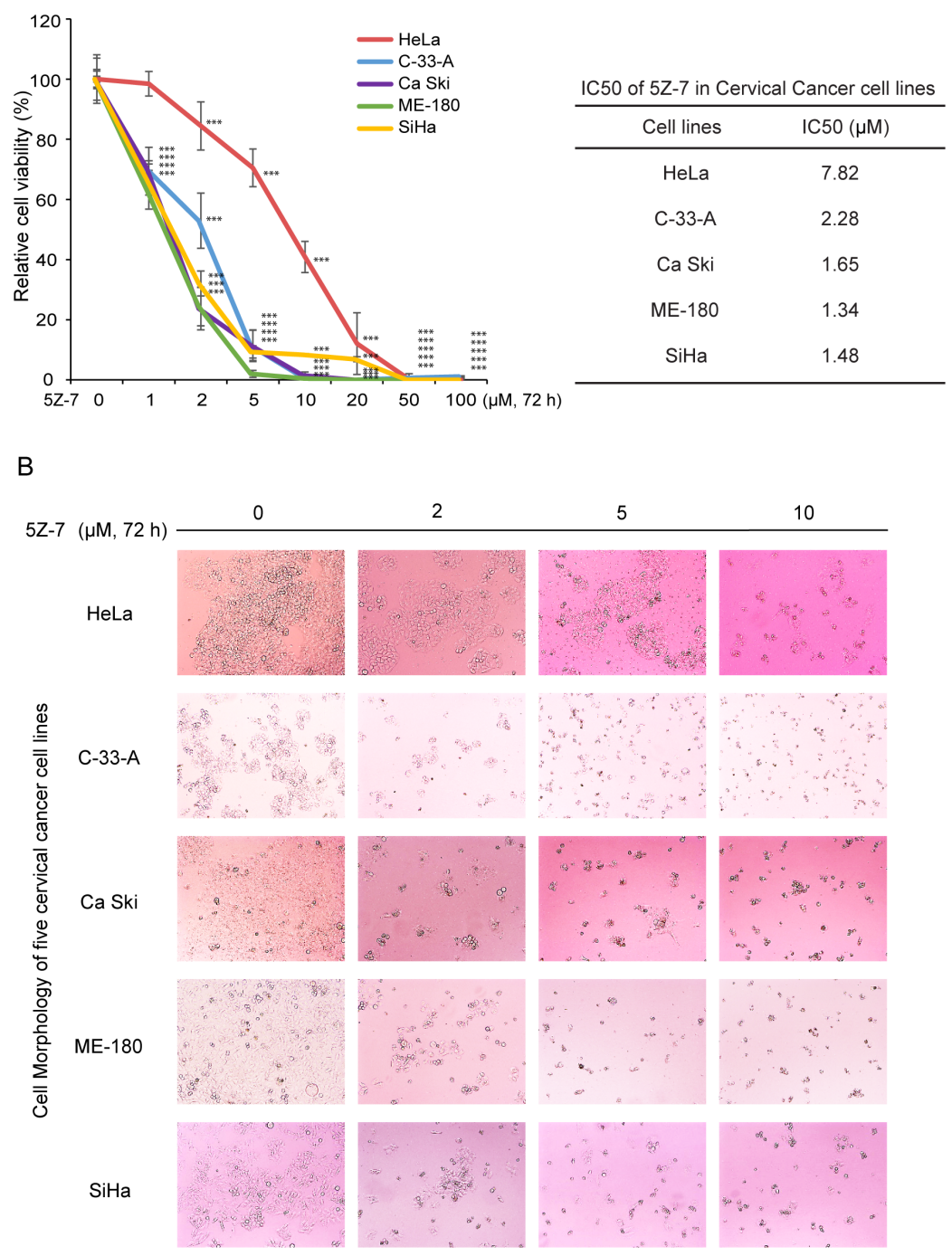

Figure 1: 5Z-7-oxozeaenol suppressescell proliferation of cervical cancer cells. (A) Five cervical cancer cell lines were seeded into 96-well plates at a concentration of $1 \times 10^{4}$ perwell and treated with indicated concentrations of 5Z-7 or DMSO. Cell viability was assessed by MTT assays after $72 \mathrm{~h}$ of exposure to drug. Data was represented as the mean standard deviation (SD) with $P<0.05(*), P<0.01$ $(* *)$, or $P<0.001(* * *)$ (ANOVA) as indicated. IC50 values of 5Z-7 in cervical cancer cell lines were listed. (B) Morphological changes of five different cervical cancer cell lines treated with increasing concentrations $(0 \mu \mathrm{M}, 2 \mu \mathrm{M}, 5 \mu \mathrm{M}, 10 \mu \mathrm{M})$ of $5 \mathrm{Z}-7$ were shown. 
A
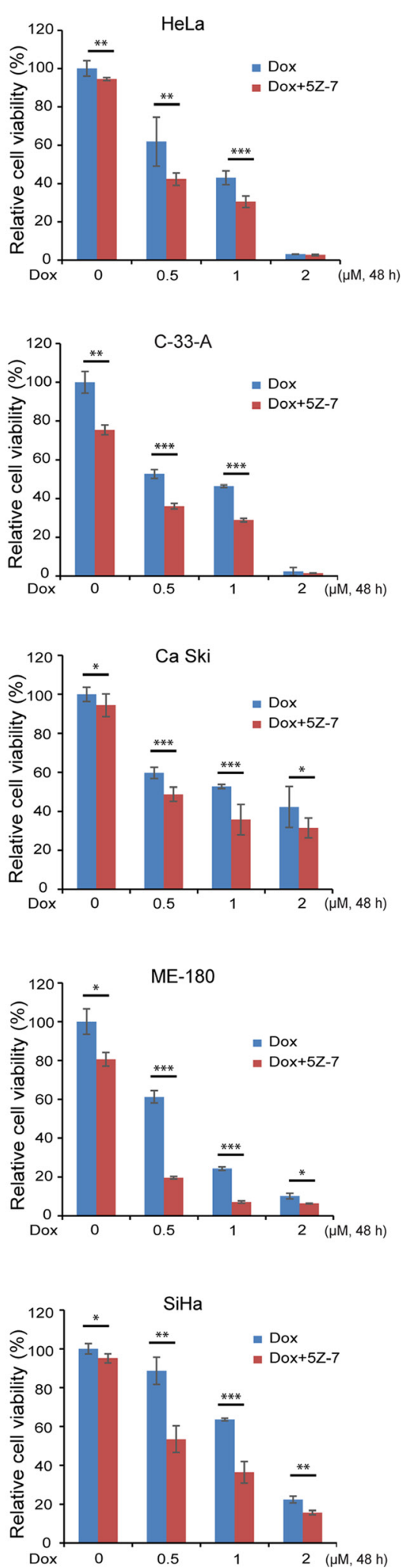

B
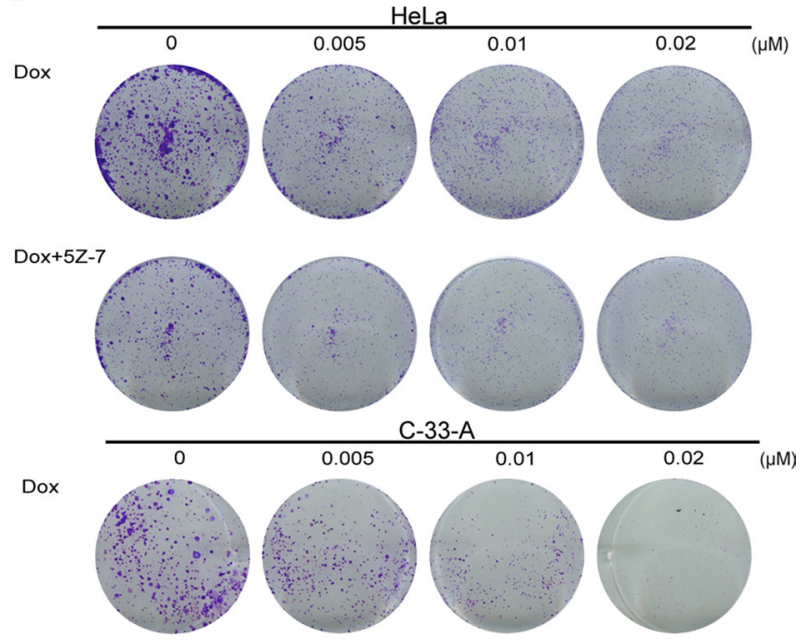

Dox+5Z-7
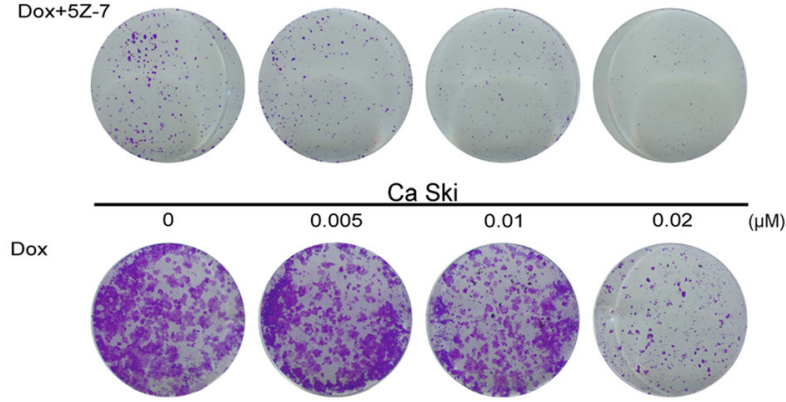

Dox+5Z-7
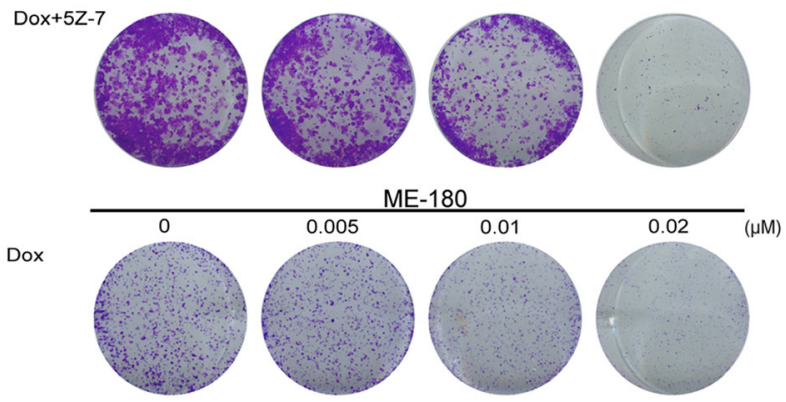

Dox+5Z-7
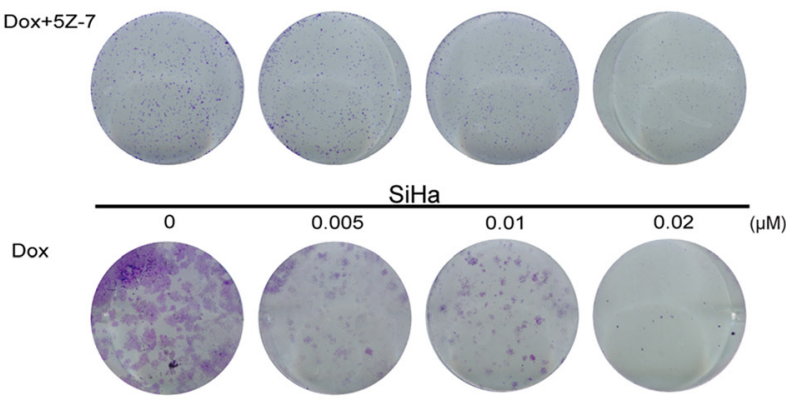

Dox+5Z-7
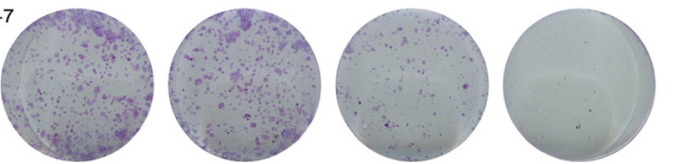

Figure 2: 5Z-7-oxozeaenol enhances Dox-induced growth inhibitory effect on cervical cancer cells. (A) HeLa, C-33-A, $\mathrm{Ca}$ Ski, ME-180 and SiHa were treated with Dox at the indicated concentrations with or without $2 \mu \mathrm{M} 5 \mathrm{Z}-7$ for $48 \mathrm{~h}$. The cell viability was then measured by CCK-8 assay. All values are expressed as the mean standard deviation (SD). $P$ values $<0.05(*),<0.01(* *)$, or $<0.001$ $\left({ }^{* * *}\right)$ were indicated. (B) Five cervical cancer cell lines wereseeded in 12 -well plates at $2 \times 10^{3}$ per well, and then incubated with Dox at the indicated concentrations with or without $2 \mu \mathrm{M} 5 \mathrm{Z}-7$ for $72 \mathrm{~h}$. The cell colonies were fixed, stained and photographed. 
enhanced the levels of reactive oxygen species (ROS) in HeLa [45], we surmise that the introduction of 5Z-7 into cervical cancer could be a potential anti-tumor strategy. Consistent with our hypothesis, our results from this in vitro study of a panel of cervical cancer cell lines demonstrate that inhibition of TAK1 activity greatly enhances Dox-induced cytotoxicity in cervical cancer. In this work, we used the TAK1 inhibitor 5Z-7, and found that the treatment of 5Z-7 could inhibit cervical cancer cell proliferation in dose-dependent manner (Figure 1A, 1B). And the combination of low concentration 5Z-7 with Dox showed significant inhibitory effect on the proliferation of cervical cancer cells. In addition, 5Z-7 enhanced the inhibitory effects of Dox on colony formation abilities (Figure 2) and anchorage-independent growth (Figure 3) of cervical cancer cells. In this study, we found that 5Z-7 significantly increased the cytotoxic effect of Dox (Figure 4) and inhibited Dox-induced NF- $\kappa \mathrm{B}, \mathrm{JNK}$, and p38 activation (Figure 5). 5Z-7 is a specific TAK1 inhibitor that works by irreversibly interacting within the ATP binding site of TAK1 [46, 47]. Thus, our results suggest that TAK1 kinase activity is required for proliferation and anchorage-independent growth of cervical cancer cells. In addition, the combinations performed well by decreasing the need of higher compound dose and longer treatment time, as well as enhancing apoptosis evidenced by more PARP and Caspase 3 cleavages on cervical cancer cell line tested. These data suggest that although single treatment of low dose 5Z-7 or Dox could not fully induce cell death, however, the combination of 5Z-7 with Dox significantly enhanced Dox-induced apoptosis and fully overcome the chemoresistance.

Another important issue is the whether HPV status would influence the efficacy of TAK1 inhibitor 5Z-7. In view that persistent infection by oncogenic HPV types is a prerequisite for the development of cervical cancer, in addition, HPV16 and HPV18 are known to cause around $70 \%$ of cervical cancer cases [48]. Thus, whether HPV status would influence the effects of 5Z-7 in cervical cancer remains as a thought-provoking issue. Importantly, 5Z-7 contributes to the Dox-induced apoptosis of both HPV positive and negative cervical cancer cell lines and, thus, could be used to treat both subtypes of cervical cancer. These data pave the way for the combination
A

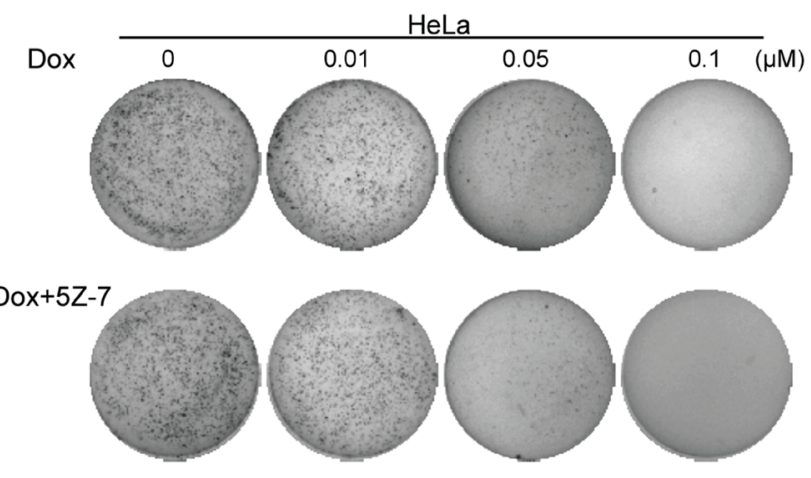

C

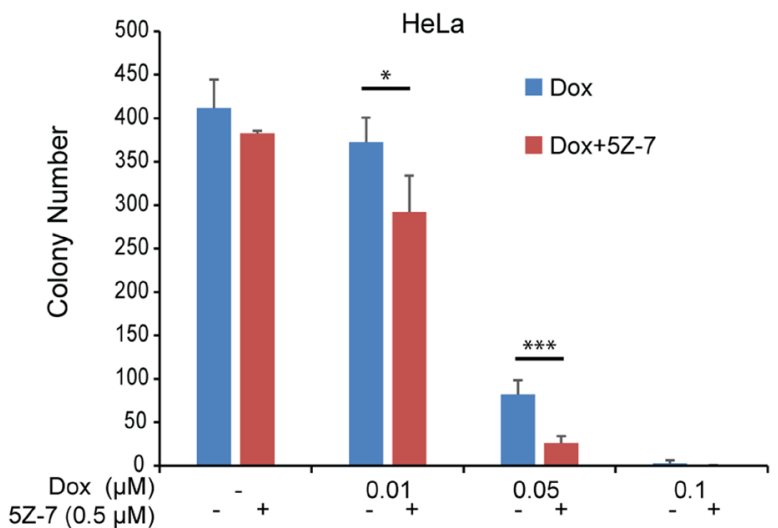

B

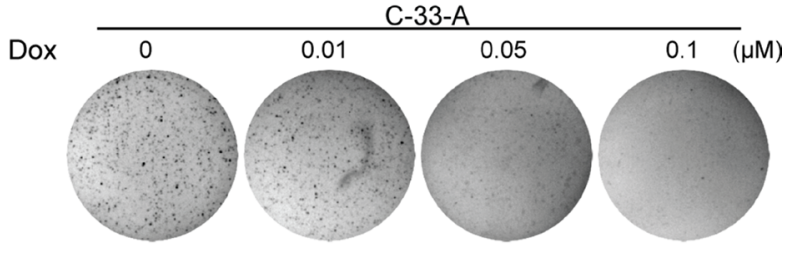

Dox $+5 Z-7$
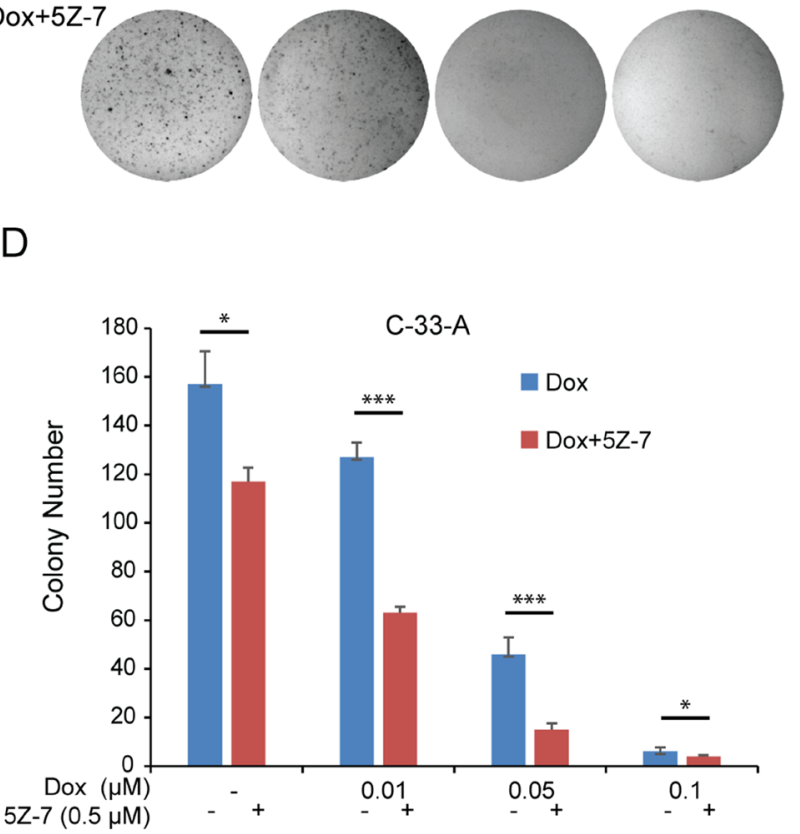

Figure 3: 5Z-7-oxozeaenol inhibits anchorage-independent growth on two cervical cancer cells. (A-B) Soft agar assays of $\mathrm{HeLa}(\mathrm{A})$ and C-33-A (B) cells treating with increasing concentrations $(0 \mu \mathrm{M}, 0.01 \mu \mathrm{M}, 0.05 \mu \mathrm{M}, 0.1 \mu \mathrm{M})$ of Dox and with or without $0.5 \mu \mathrm{M} 5 \mathrm{Z}-7$ were conducted. Cell colonies were stained and photographed after 14 days. $(\mathbf{C}-\mathbf{D})$ The colony numbers of HeLa $(\mathrm{C})$ and C-33-A (D) cells were calculated. All values are expressed as the mean standard deviation (SD). $P$ values $<0.05(*),<0.01(* *)$, or $<0.001$ $(* * *)$ were indicated. 
of 5Z-7 with Dox to be used as a promising therapeutic strategy for both anti-HPV positive and anti-HPV negative cervical cancer.

In summary, our work shows that pharmacological inhibition of TAK1 activity blocks genotoxic stressinduced TAK1 signaling and pushes cervical cancer cells towards death pathway. Our results provide an understanding of TAK1-dependent survival pathways in response to chemotherapy and valuable data for potential clinical applications of TAK1 inhibitors like 5Z-7 to treat cervical cancer. It's the first time that we show TAK1 inhibitor 5Z-7-oxozeaenol could be used for the treatment of cervical cancer. Meanwhile, TAK1 inhibitor 5Z-7oxozeaenol shows inhibitory effects by attenuating cell proliferation and inducing apoptosis on both HPV-positive and HPV-negative cell lines. In addition, the combination studies of 5Z-7 with chemotherapy sheds light on the process of chemoresistance of refractory cervical cancer.

\section{MATERIALS AND METHODS}

\section{Cell lines and cell culture}

HeLa cells were grown in DMEM (Lonza, Walkersville, MD, USA) containing 10\% fetal bovine serum (FBS, SAFC Biosciences), 100 units/mL penicillin, and $100 \mu \mathrm{g} / \mathrm{mL}$ streptomycin. C-33-A, Ca Ski, ME-180 and $\mathrm{SiHa}$ cells were grown in RPMI 1640 (Cellgro) containing $10 \%$ fetal bovine serum (FBS, SAFC Biosciences), 100 units $/ \mathrm{mL}$ penicillin, and $100 \mu \mathrm{g} / \mathrm{mL}$ streptomycin. Cells were cultivated in $5 \% \mathrm{CO}_{2}$ at $37^{\circ} \mathrm{C}$.

\section{Antibodies and reagents}

Anti-JNK (9252), anti-phospho-JNK (9251), antiIкB $\alpha$ (9242), anti-p38 (9212), anti-phospho-p38 (9211), and anti-PARP (9532), anti-Caspase 3 (9662) primary

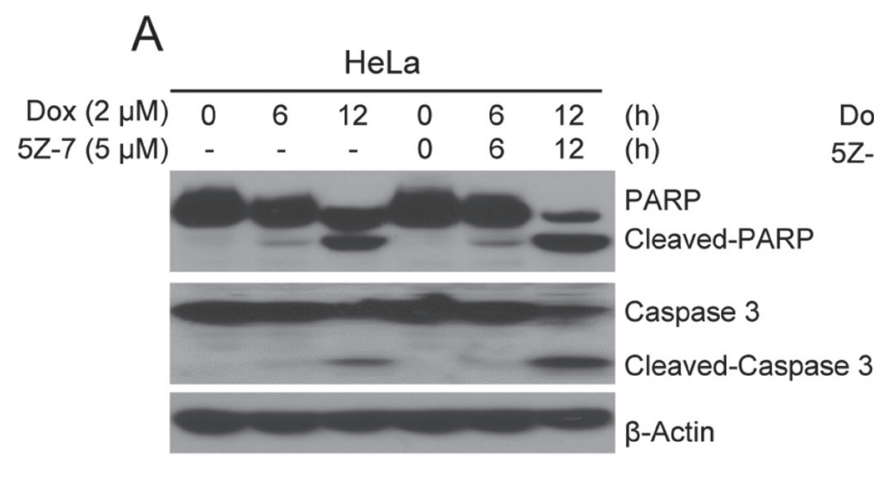

B
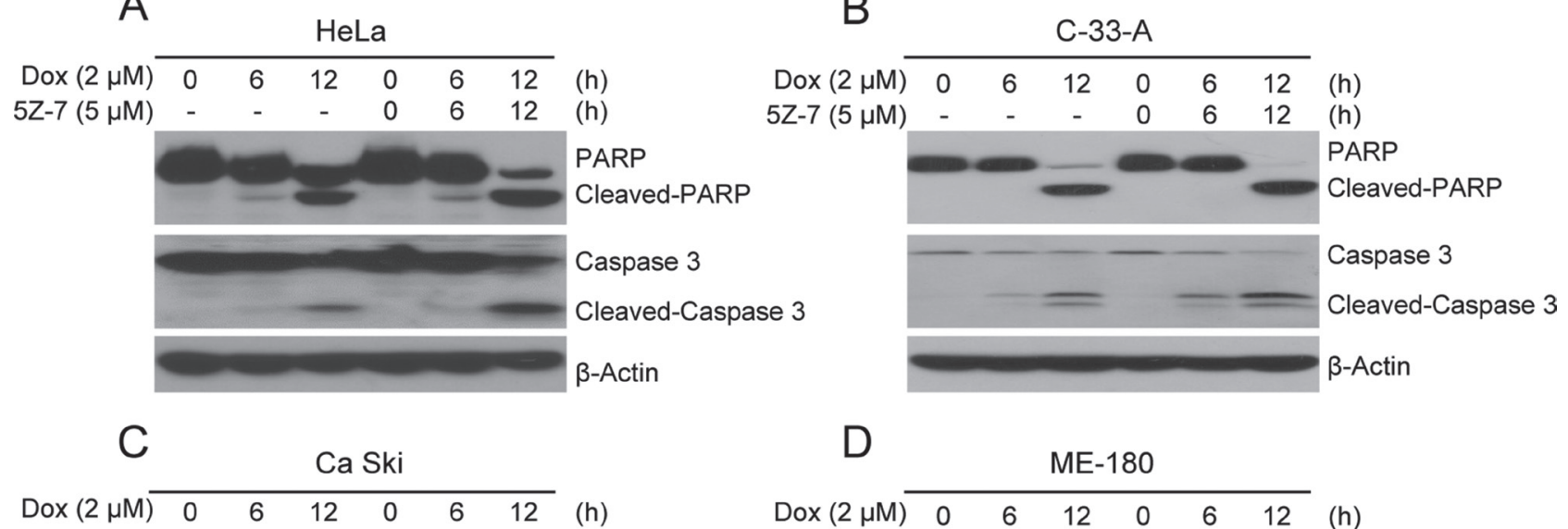

$5 Z-7(5 \mu \mathrm{M}) \quad-\quad-\quad-\quad 00612$

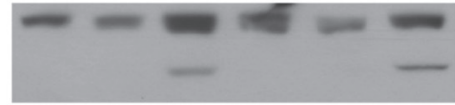

PARP

Cleaved-PARP

\begin{tabular}{cccccccc}
$\mathrm{D}$ & \multicolumn{7}{c}{ ME-180 } \\
\cline { 2 - 7 } $\operatorname{Dox}(2 \mu \mathrm{M})$ & 0 & 6 & 12 & 0 & 6 & 12 & $(\mathrm{~h})$ \\
$5 Z-7(5 \mu \mathrm{M})$ & - & - & - & 0 & 6 & 12 & $(\mathrm{~h})$
\end{tabular}

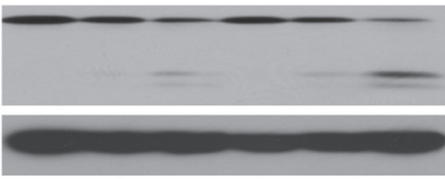

Caspase 3

Cleaved-Caspase 3

$\beta$-Actin
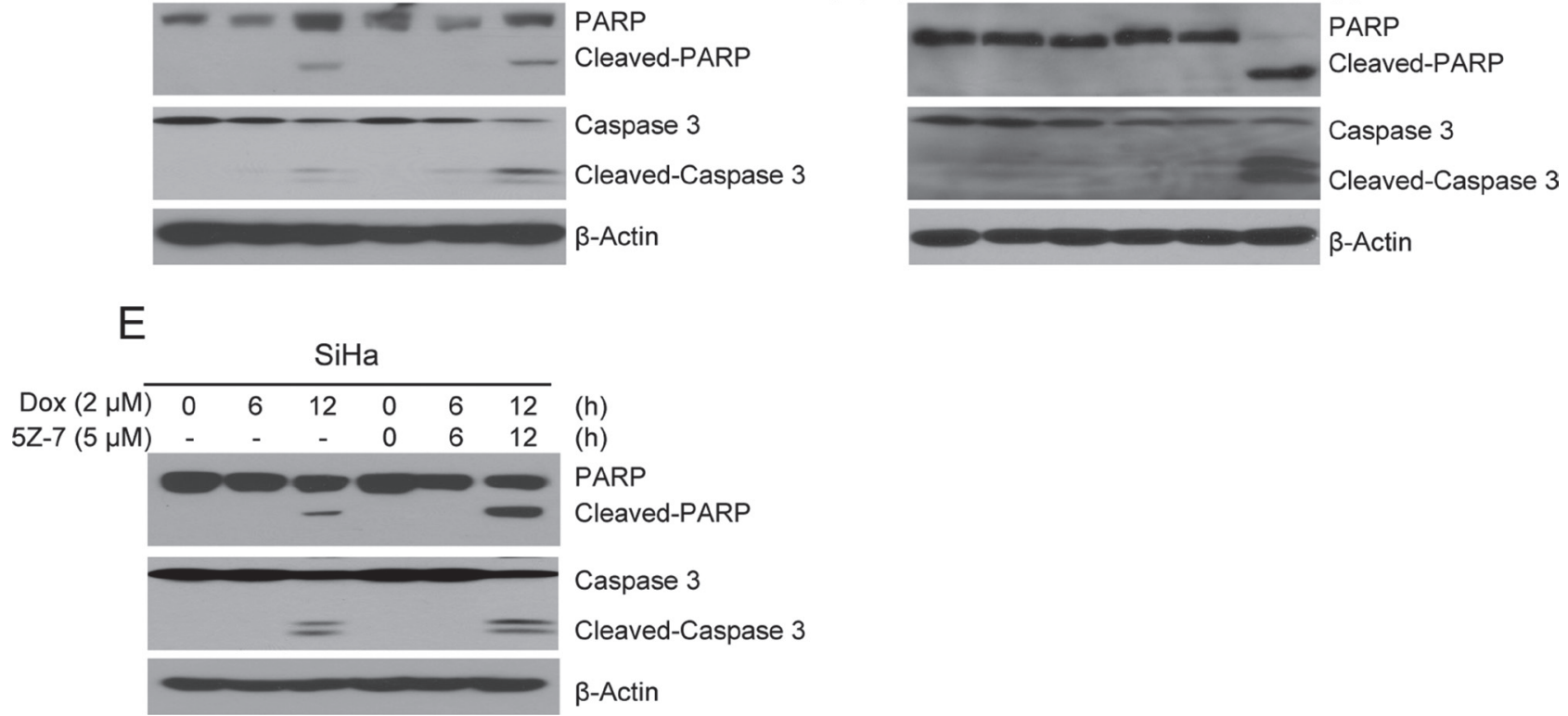

(h)

(h)

PARP

Cleaved-PARP

Caspase 3

Cleaved-Caspase 3

$\beta$-Actin

Figure 4: 5Z-7-oxozeaenol promotes Dox-induced apoptosis. (A-E) HeLa (A) and C-33-A (B), Ca Ski (C), ME-180 (D), SiHa (E) cells were treated with Dox at the indicated time points $(0,6,12 \mathrm{~h})$ with or without 5Z-7 and protein extracts were subjected to SDS-PAGE and immunoblotted for anti-PARP, and anti-Caspase 3 antibodies. $\beta$-Actin was detected as a loading control for all whole cell extracts. 
antibodies were obtained from Cell Signaling Technology (Danvers, MA, USA). Anti-mouse (7076) and antirabbit (7074) secondary antibodies were obtained from Cell Signaling Technology (Danvers, MA, USA). Anti$\beta$-Actin (A2228) primary antibody was obtained from Sigma (Sigma-Aldrich Corp, St. Louis, MO, USA). 5Z-7oxozeaenol (499610) was acquired from Calbiochem. Dox (D1515) was purchased from Sigma (Sigma-Aldrich Corp, St. Louis, MO, USA).

\section{Cell viability assay}

The MTT assay were conducted using MTT (MKBH9792V) (Sigma-Aldrich, Spring, TX, USA) following the manufacturer's instructions. Briefly, the cells were seeded in 96-well plates at the density of $5 \times 10^{3}$ cells per well. After $24 \mathrm{~h}$ of incubation at $37^{\circ} \mathrm{C}$, cells were either allowed to grow in media alone or in media containing increasing concentrations of 5Z-7 for $72 \mathrm{~h}$. Cells were then observed and photographed by optical microscope. $10 \mu \mathrm{l}$ of MTT was added into each well, and the cells were incubated for another $2 \mathrm{~h}$. Then, $50 \mu \mathrm{l}$ of DMSO was added into each well, and the cells were incubated for another $10 \mathrm{~min}$. The absorbance of each well was measured at $540 \mathrm{~nm}$ and plotted for the cell viability curve. The CCK-8 assay were conducted as previously described $[37,49]$. Briefly, cells were plated in 96-well plates at a concentration of $1 \times 10^{4}$ cells per well. After incubating the plate for $24 \mathrm{~h}$ at $37^{\circ} \mathrm{C}$, cells were treated with various concentrations of Dox, 5Z-7, or a combination for the indicated duration. $72 \mathrm{~h}$ later, replaced medium with mixture $(10 \mu \mathrm{L}$ of Cell Counting Kit-8 (Dojindo Laboratories) solution \& $190 \mu \mathrm{L}$ DMEM or RPMI 1640 medium) and incubated for another $1 \mathrm{~h}$ at $37^{\circ} \mathrm{C}$. The relative cell viability was quantified by measuring the

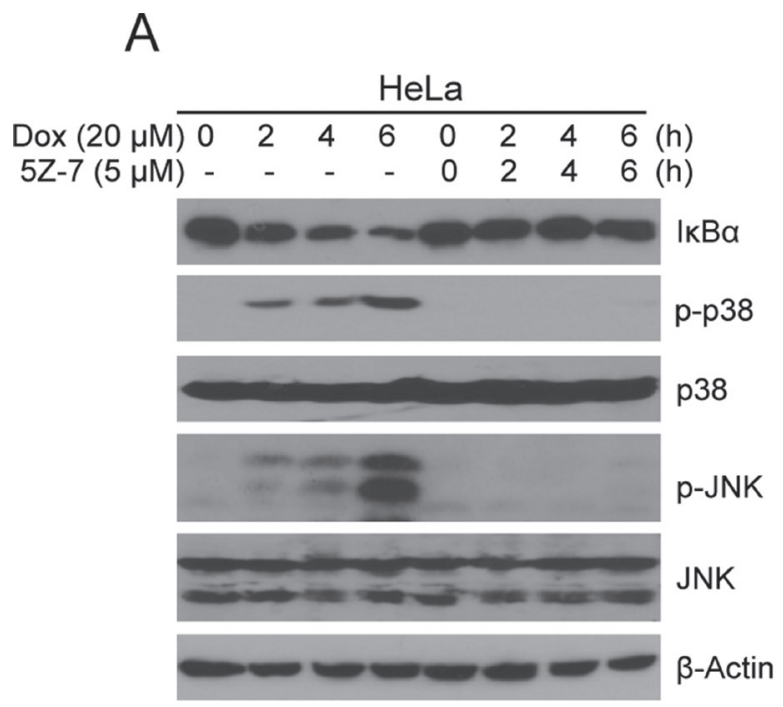

absorbance at $450 \mathrm{~nm}$. Each experiment was performed in triplicates.

\section{Cell imaging}

Cervical cancer cell lines (HeLa, C-33-A, Ca Ski, ME180 and $\mathrm{SiHa}$ ) were seeded in 96-well plates at appropriate concentrations. Cell morphologies were observed and captured by an optical microscope after $72 \mathrm{~h}$ of treatment with indicated concentrations $(0 \mu \mathrm{M}, 2 \mu \mathrm{M}, 5 \mu \mathrm{M}, 10 \mu \mathrm{M})$ of $5 Z-7$.

\section{Colony formation assay}

Cervical cancer cells were seeded in 12-well plates at $2 \times 10^{3}$ cells per well, then treated with single Dox or the combo (Dox \& 5Z-7) at indicated concentrations. After $72 \mathrm{~h}$, the medium containing drug were replaced with fresh medium without drug. Two weeks later, cells were fixed and stained with methanol/crystal violet and photographed. Each experiment was performed in triplicates.

\section{Soft agar assay}

The experiments were performed as previously described [37]. Briefly, a 5\% solution of agar (214220, Difco Laboratories) was autoclaved. Followed by cooling to $56^{\circ} \mathrm{C}$ in a water bath. A $0.5 \%$ lower gel (mixture of agar, DMEM or RPMI 1640 containing 10\% FBS) was plated in 6-well plates ( $2 \mathrm{~mL}$ per well). After this layer solidified, a $0.3 \%$ upper gel (mixture of agar, DMEM or RPMI 1640 media with 10\% FBS) was made and mixed with each cell line at a concentration of $1 \times 10^{4}$ cells per well (1.5 mL per well). Cells grew at $37^{\circ} \mathrm{C}$ in $5 \% \mathrm{CO}_{2}$ for another 2 weeks (14 days) and stained with crystal

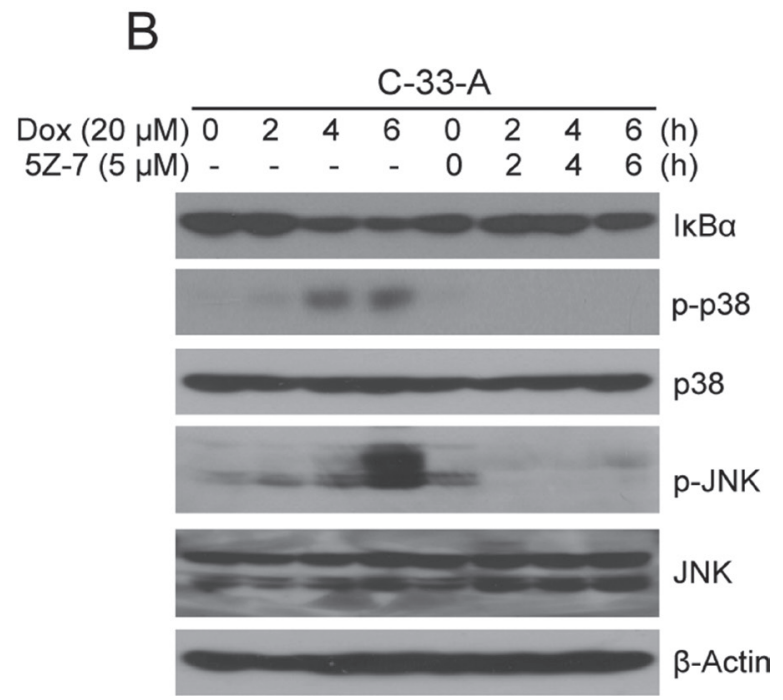

Figure 5: 5Z-7-oxozeaenol inhibits Dox-induced NF-кB, JNK and p38 activation. (A-B) HeLa (A) and C-33-A (B) cells were treated with Dox at the indicated time points $(0,2,4,6 \mathrm{~h})$ with or without $5 \mathrm{Z}-7$ and protein extracts were subjected to SDS-PAGE and immunoblotted with the indicated antibodies. $\beta$-Actin was detected as a loading control for all whole cell extracts. 
violet. The colonies were photographed and counted by VersaDoc Imaging System (Bio-rad). Each experiment was performed in triplicates.

\section{Immunoblotting assay}

Cell lysates were harvested by washing cells with ice-cold PBS twice and then lysed cells with RIPA lysis buffer (25 mM HEPES at PH 7.7, $135 \mathrm{mM} \mathrm{NaCl}$, $1 \%$ Triton X-100, $25 \mathrm{mM}$ b-glycerophosphate, $0.1 \mathrm{mM}$ sodium orthovanadate, $0.5 \mathrm{mM}$ phenylmethylsulfonyl fluoride, $1 \mathrm{mM}$ dithiothreitol, $10 \mu \mathrm{g} / \mathrm{mL}$ aprotinin, $10 \mu \mathrm{g} / \mathrm{mL}$ leupeptin, $1 \mathrm{mM}$ Benzamidine, $20 \mathrm{mM}$ disodium p-nitrophenylphosphate, and phosphatase inhibitor cocktail 2 and 3 (p5726 and p0044, Sigma)). Supernatants were collected, after centrifuging at 13,000 rpm for $15 \mathrm{~min}$ at $4^{\circ} \mathrm{C}$. And then supernatants were boiled with loading followed by separated in SDS-PAGE (polyacrylamide gel electrophoresis). And SDS-PAGE were transferred to PVDF membranes. The PVDF membranes were blocked in TBST with 5\% dry milk and then incubated with corresponding primary antibodies overnight at $4{ }^{\circ} \mathrm{C}$. The membranes were washed by TBST and incubated with corresponding secondary antibodies for $1 \mathrm{~h}$ at room temperature $\left(25^{\circ} \mathrm{C}\right)$. The membranes were then visualized by the ECL-Plus Western detection system (GE Health Care, Buckinghamshire, UK) after washed by TBST for 3 times (15 min/each time). The anti- $\beta$-Actin antibodies were used as a loading control for whole cell extracts in all samples.

\section{Statistical analysis}

Two-tailed Student's $t$-test and ANOVA were used to determine the statistical significance among drug treatment group and control group. Each assay was repeated at least twice, and representative results were presented. All values are expressed as the mean standard deviation (SD). $P<0.05$ was considered statistically significant.

\section{Abbreviations}

NF-кB, nuclear factor-kappa B; 5Z-7, 5Z-7oxozeaenol; Dox, Doxorubicin; VP-16, etoposide; HPV, human papillomavirus; MAPK, mitogen-activated protein kinase; DMSO, dimethyl sulfoxide; TGF- $\beta$, transforming growth factor- $\beta$; I $\mathrm{I} \mathrm{B} \alpha$, nuclear factor of kappa light polypeptide gene enhancer in B-cells inhibitor, alpha; IKK, IкB kinase; PARP, poly ADP ribose polymerase.

\section{Authors' contributions}

Conceived and designed the experiments: S.S., J.Y., S.G., F.Z.. Performed the experiments: S.G., Y.Z., H.Z., X.X., S.B., H.L.. Analyzed the data: S.S., J.Y., S.G., J.L., J.Z.. Contributed reagents/materials/analysis tools: X.X.,
Y.Y.. Wrote the paper: S.G., J.L., S. W.. Analyzed value profiles: J.Y., S.G., J.L.

\section{ACKNOWLEDGMENTS}

We thank Dr. Ramondetta (M D. Anderson, TX, USA) for providing the cervical cancer cell lines C-33-A, $\mathrm{SiHa}, \mathrm{Ca}$ Ski, ME-180 described in this paper.

\section{CONFLICTS OF INTEREST}

The authors have declared that no competing interests exist.

\section{FUNDING}

This work was supported by the grant from the NIH grant 1R01NS072420 (J.Y.), and NINDS grant 1R21NS085467 (J.Y.). This work were also supported by the grant from the Science Foundation of Xinjiang (No. 2013211A018), and the Graduate Research and Innovation Project of Xinjiang (No. XJGRI2013043). The funders had no role in study design, data collection and analysis, decision to publish, or preparation of the manuscript.

\section{REFERENCES}

1. Jemal A, Bray F, Center MM, Ferlay J, Ward E, Forman D. Global cancer statistics. CA Cancer J Clin. 2011; 61:69-90.

2. Shen MR, Hsu YM, Hsu KF, Chen YF, Tang MJ, Chou CY. Insulin-like growth factor 1 is a potent stimulator of cervical cancer cell invasiveness and proliferation that is modulated by alphavbeta3 integrin signaling. Carcinogenesis. 2006; 27:962-971.

3. Hu X, Schwarz JK, Lewis JS Jr, Huettner PC, Rader JS, Deasy JO, Grigsby PW, Wang X. A microRNA expression signature for cervical cancer prognosis. Cancer Res. 2010; 70:1441-1448.

4. Cornelio DB, Roesler R, Schwartsmann G. Emerging therapeutic agents for cervical cancer. Recent Pat Anticancer Drug Discov. 2009; 4:196-206.

5. Morrison R, Schleicher SM, Sun Y, Niermann KJ, Kim S, Spratt DE, Chung CH, Lu B. Targeting the mechanisms of resistance to chemotherapy and radiotherapy with the cancer stem cell hypothesis. J Oncol. 2011; 2011:941876.

6. Frosina G. DNA repair and resistance of gliomas to chemotherapy and radiotherapy. Mol Cancer Res. 2009; 7:989-999.

7. Gilbert LA, Hemann MT. Chemotherapeutic resistance: surviving stressful situations. Cancer Res. 2011; 71:5062-5066.

8. Sen R, Baltimore D. Inducibility of kappa immunoglobulin enhancer-binding protein Nf-kappa B by a posttranslational mechanism. Cell. 1986; 47:921-928. 
9. Newton K, Dixit VM. Signaling in innate immunity and inflammation. Cold Spring Harb Perspect Biol. 2012; 4.

10. Oeckinghaus A, Hayden MS, Ghosh S. Crosstalk in NFkappaB signaling pathways. Nat Immunol. 2011; 12:695-708.

11. Li F, Sethi G. Targeting transcription factor NF-kappaB to overcome chemoresistance and radioresistance in cancer therapy. Biochim Biophys Acta. 2010; 1805:167-180.

12. Aggarwal BB, Sung B. NF-kappaB in cancer: a matter of life and death. Cancer Discov. 2011; 1:469-471.

13. Chaturvedi MM, Sung B, Yadav VR, Kannappan R, Aggarwal BB. NF-kappaB addiction and its role in cancer: 'one size does not fit all'. Oncogene. 2011; 30:1615-1630.

14. Ethiraj P, Veerappan K, Samuel S, Sivapatham S. Interferon beta improves the efficacy of low dose cisplatin by inhibiting NF-kappaB/p-Akt signaling on HeLa cells. Biomed Pharmacother. 2016; 82:124-132.

15. He A, Ji R, Shao J, He C, Jin M, Xu Y. TLR4-MyD88TRAF6-TAK1 Complex-Mediated NF-kappaB Activation Contribute to the Anti-Inflammatory Effect of V8 in LPSInduced Human Cervical Cancer SiHa Cells. Inflammation. 2016; 39:172-181.

16. Chen ZJ, Bhoj V, Seth RB. Ubiquitin, TAK1 and IKK: is there a connection? Cell Death Differ. 2006; 13:687-692.

17. Hayden MS, Ghosh S. Shared principles in NF-kappaB signaling. Cell. 2008; 132:344-362.

18. Sun SC, Ley SC. New insights into NF-kappaB regulation and function. Trends Immunol. 2008; 29:469-478.

19. Shim JH, Xiao C, Paschal AE, Bailey ST, Rao P, Hayden MS, Lee KY, Bussey C, Steckel M, Tanaka N, Yamada G, Akira S, Matsumoto K, et al. TAK1, but not $\mathrm{TAB} 1$ or TAB2, plays an essential role in multiple signaling pathways in vivo. Genes Dev. 2005; 19:2668-2681.

20. Wang Z, Zhang H, Shi M, Yu Y, Wang H, Cao WM, Zhao Y, Zhang H. TAK1 inhibitor NG25 enhances doxorubicinmediated apoptosis in breast cancer cells. Sci Rep. 2016; 6:32737.

21. Wu ZH, Wong ET, Shi Y, Niu J, Chen Z, Miyamoto S, Tergaonkar V. ATM- and NEMO-dependent ELKS ubiquitination coordinates TAK1-mediated IKK activation in response to genotoxic stress. Mol Cell. 2010; 40:75-86.

22. Yang Y, Xia F, Hermance N, Mabb A, Simonson S, Morrissey S, Gandhi P, Munson M, Miyamoto S, Kelliher MA. A cytosolic ATM/NEMO/RIP1 complex recruits TAK1 to mediate the NF-kappaB and p38 mitogen-activated protein kinase (MAPK)/MAPK-activated protein 2 responses to DNA damage. Mol Cell Biol. 2011; 31:2774-2786.

23. Hinz M, Stilmann M, Arslan SC, Khanna KK, Dittmar G, Scheidereit C. A cytoplasmic ATM-TRAF6-cIAP1 module links nuclear DNA damage signaling to ubiquitin-mediated NF-kappaB activation. Mol cell. 2010; 40:63-74.

24. Jin HS, Lee DH, Kim DH, Chung JH, Lee SJ, Lee TH. cIAP1, cIAP2, and XIAP act cooperatively via nonredundant pathways to regulate genotoxic stress-induced nuclear factor-kappaB activation. Cancer Res. 2009; 69:1782-1791.
25. Liang L, Fan Y, Cheng J, Cheng D, Zhao Y, Cao B, Ma L, An L, Jia W, Su X, Yang J, Zhang H. TAK1 ubiquitination regulates doxorubicin-induced NF-kappaB activation. Cell Signal. 2013; 25:247-254.

26. Singh A, Sweeney MF, Yu M, Burger A, Greninger P, Benes C, Haber DA, Settleman J. TAK1 inhibition promotes apoptosis in KRAS-dependent colon cancers. Cell. 2012; 148:639-650.

27. Park B, Sung B, Yadav VR, Chaturvedi MM, Aggarwal BB. Triptolide, histone acetyltransferase inhibitor, suppresses growth and chemosensitizes leukemic cells through inhibition of gene expression regulated by TNF-TNFR1TRADD-TRAF2-NIK-TAK1-IKK pathway. Biochem Pharmacol. 2011; 82:1134-1144.

28. Broutin S, Stewart A, Thavasu P, Paci A, Bidart JM, Banerji U. Insights into significance of combined inhibition of MEK and m-TOR signalling output in KRAS mutant non-small-cell lung cancer. Br J Cancer. 2016; 115:549-552.

29. Ridder DA, Schwaninger M. TAK1 inhibition for treatment of cerebral ischemia. Exp Neurol. 2013; 239:68-72.

30. Cao H, Lu J, Du J, Xia F, Wei S, Liu X, Liu T, Liu Y, Xiang M. TAK1 inhibition prevents the development of autoimmune diabetes in NOD mice. Sci Rep. 2015; 5:14593.

31. Wang JS, Wu D, Huang DY, Lin WW. TAK1 inhibitioninduced RIP1-dependent apoptosis in murine macrophages relies on constitutive TNF-alpha signaling and ROS production. J Biomed Sci. 2015; 22:76.

32. Wei L, Ying L, Chunxia Y. Erratum to: Inhibition of ovarian cancer cell growth by a novel TAK1 inhibitor LYTAK1. Cancer Chemother Pharmacol. 2015; 76:1099.

33. Wu J, Powell F, Larsen NA, Lai Z, Byth KF, Read J, Gu RF, Roth M, Toader D, Saeh JC, Chen H. Mechanism and in vitro pharmacology of TAK1 inhibition by (5Z)-7Oxozeaenol. ACS Chem Biol. 2013; 8:643-650.

34. Kilty I, Jones LH. TAK1 selective inhibition: state of the art and future opportunities. Future Med Chem. 2015; 7:23-33.

35. Fakhouri L, El-Elimat T, Hurst DP, Reggio PH, Pearce CJ, Oberlies NH, Croatt MP. Isolation, semisynthesis, covalent docking and transforming growth factor beta-activated kinase 1 (TAK1)-inhibitory activities of (5Z)-7-oxozeaenol analogues. Bioorg Med Chem. 2015; 23:6993-6999.

36. Acuna UM, Wittwer J, Ayers S, Pearce CJ, Oberlies NH, EJ DEB. Effects of (5Z)-7-oxozeaenol on the oxidative pathway of cancer cells. Anticancer Res. 2012; 32:2665-2671.

37. Fan Y, Cheng J, Vasudevan SA, Patel RH, Liang L, Xu X, Zhao Y, Jia W, Lu F, Zhang H, Nuchtern JG, Kim ES, Yang J. TAK1 inhibitor 5Z-7-oxozeaenol sensitizes neuroblastoma to chemotherapy. Apoptosis. 2013; 18:1224-1234.

38. Zhang J, Li B, Wu H, Ou J, Wei R, Liu J, Cai W, Liu X, Zhao S, Yang J, Zhou L, Liu S, Liang A. Synergistic action of 5Z-7-oxozeaenol and bortezomib in inducing apoptosis of Burkitt lymphoma cell line Daudi. Tumour Biol. 2016; 37:531-539. 
39. Zhang J, Wu H, Li P, Zhao Y, Liu M, Tang H. NF-kappaBmodulated miR-130a targets TNF-alpha in cervical cancer cells. J Transl Med. 2014; 12:155.

40. Xia L, Xue XZ. Immunohistochemical study of NF-kappaB p65, c-IAP2 and caspase-3 expression in cervical cancer. Oncol Lett. 2012; 3:839-844.

41. Liu W, Gao Q, Chen K, Xue X, Li M, Chen Q, Zhu G, Gao Y. Hiwi facilitates chemoresistance as a cancer stem cell marker in cervical cancer. Oncol Rep. 2014; 32:1853-1860.

42. Xie Q, Liang J, Rao Q, Xie X, Li R, Liu Y, Zhou H, Han J, Yao T, Lin Z. Aldehyde dehydrogenase 1 expression predicts chemoresistance and poor clinical outcomes in patients with locally advanced cervical cancer treated with neoadjuvant chemotherapy prior to radical hysterectomy. Ann Surg Oncol. 2016; 23:163-170.

43. Zeng L, Zhen Y, Chen Y, Zou L, Zhang Y, Hu F, Feng J, Shen J, Wei B. Naringin inhibits growth and induces apoptosis by a mechanism dependent on reduced activation of NFkappaB/COX2caspase-1 pathway in HeLa cervical cancer cells. Int J Oncol. 2014; 45:1929-1936.

44. Kuk H, Hutchenreuther J, Murphy-Marshman H, Carter D, Leask A. 5Z-7-Oxozeanol inhibits the effects of TGFbetal on human gingival fibroblasts. PLoS One. 2015; 10:e0123689.
45. Acuna UM, Wittwer J, Ayers S, Pearce CJ, Oberlies NH, EJ DEB. Effects of (5Z)-7-oxozeaenol on MDA-MB-231 breast cancer cells. Anticancer Res. 2012; 32:2415-2421.

46. Hanahan D, Weinberg RA. Hallmarks of cancer: the next generation. Cell. 2011; 144:646-674.

47. Ninomiya-Tsuji $J$, Kajino $T$, Ono $K$, Ohtomo $T$, Matsumoto M, Shiina M, Mihara M, Tsuchiya M, Matsumoto K. A resorcylic acid lactone, 5Z-7-oxozeaenol, prevents inflammation by inhibiting the catalytic activity of TAK1 MAPK kinase kinase. J Biol Chem. 2003; 278:18485-18490.

48. Garland SM, Kjaer SK, Munoz N, Block SL, Brown DR, DiNubile MJ, Lindsay BR, Kuter BJ, Perez G, DominiakFelden G, Saah AJ, Drury R, Das R, et al. Impact and effectiveness of the quadrivalent human papillomavirus vaccine: a systematic review of ten years of real-world experience. Clin Infect Dis. 2016; 63:519-27.

49. Shang X, Burlingame SM, Okcu MF, Ge N, Russell HV, Egler RA, David RD, Vasudevan SA, Yang J, Nuchtern JG. Aurora $\mathrm{A}$ is a negative prognostic factor and a new therapeutic target in human neuroblastoma. Mol Cancer Ther. 2009; 8:2461-2469. 